\title{
Effect of viscoelastic and surface properties on tack, peel adhesion and shear strength of polymer blends applied as hot melt pressure sensitive adhesive models comprising tackifying agents of various chemical nature
}

\author{
T. Abboud ${ }^{1 *}$, A. Wutzler ${ }^{2}$, H-J. Radusch ${ }^{2,3}$ \\ ${ }^{1}$ Arakawa Europe GmbH, Düsseldorfer Str. 13, 65760 Eschborn, Germany \\ ${ }^{2}$ Polymer Service GmbH Merseburg (PSM), Eberhard-Leibnitz-Str. 2, 06217 Merseburg, Germany \\ ${ }^{3}$ Martin Luther University Halle-Wittenberg, Center of Engineering Sciences, 06099 Halle (Saale), Germany
}

\begin{abstract}
Viscoelastic and surface properties of polymer blends prepared as models of hot melt pressure sensitive adhesives (HMPSA) were investigated and the correlation to tack, peel, and shear adhesion properties was discussed. Three different types of tackifiers, which present a softening point of ca. $100^{\circ} \mathrm{C}$ as well as different compatibility degree with the midblock and the end-block of poly(styrene-block-isoprene-block-styrene) (SIS), were employed. A good association degree between the midblock and the tackifiers was observed. Surface energy was used to evaluate the blend compatibility trend. The blends presented lower surface energy than the pure materials due to non-polar and acid-base interactions. This is a feature of compatible blends. PSA character was observed based on the obtained results of tack and peel for the blends and it is a consequence of the adequate degree of compatibility of the tackifiers and the midblock. The compatibility of the tackifiers and the end-block influenced shear adhesion. Rosin ester resin showed a better association with the styrenic domains. The second maximum of the loss modulus $\left(G^{\prime \prime}\right)$ curve for a blend containing rosin resin shifted to lower temperatures in comparison to blends containing the other investigated resins. The lowest holding power values were measured for the blends containing rosin ester resin. The styrene domains were pronouncedly disturbed by this resin.
\end{abstract}

Keywords: polymer blends and alloys, adhesion, viscoelasticity

\section{Introduction}

Pressure-sensitive adhesive (PSA) is a particular kind of adhesive in which the bond between two parts is formed with no or light pressure and they are permanently tacky $[1,2]$. They are generally blends of the base polymer, tackifier and plasticizer. Tackifiers are low molecular weight materials, with a high glass transition temperature and amorphous [3]. The reason for adding a tackifier to a PSA is to bring stickiness to the final material. Pressure-sensitive adhesives can be blended and coated by means of different technologies. Based on the technology employed,
PSAs can be classified as solvent-borne, water-borne and hot melt. Hot melt pressure-sensitive adhesive (HMPSA) is an environmentally friendly type of PSA, since only heat is needed to prepare and coat the material $[4,5]$. It is well known that the processing method influences the polymer blends final properties. For example, preparing a blend by solvent or by mechanical mixing may lead to miscible or immiscible systems with different homogeneities [6]. A miscible polymeric blend is a polymeric mixture obeying the thermodynamic criteria of miscibility, while in an immiscible polymeric blend, more phases 
are observed. Thermodynamic relationships also describe immiscibility [7, 8]. A compatible polymer blend is an immiscible polymer blend without molecular miscibility, which exhibits macroscopically uniform properties generating satisfactory engineering properties [7].

The adhesive performance of PSAs has been extensively researched in connection to their viscoelastic properties [2,9-15]. This work aims to analyze adhesive performance not only by assessing viscoelastic properties but also supported by surface properties.

Aubrey et al. [16] investigated the viscoelastic behavior of natural rubber and two different tackifiers. They observed by means of dynamic mechanical spectroscopy investigation in frequency sweep a reduction of the rubbery plateau width and a shift of the transition zone to lower frequencies. In the terminal zone, they observed a shift to higher frequencies.

Class and Chu $[3,17,18]$ explored the viscoelastic properties of a rubber and resin mixture regarding resin structure, molecular weight, and concentration. It was observed that when compatibility between rubber and resin exists, a significant shift in loss factor peak and a decrease of storage modulus in the rubbery plateau region follows.

It is well established that compatibility among the components in a polymer blend is an important factor that affects its final properties. It is known that the compatibility of the tackifier used in the polymer blend with the midblock or/and with the endblock of the triblock copolymer influences the adhesive performance [19]. By selecting tackifiers of different chemical nature and degree of association with each block, the effect of compatibility among the components of the blend is assessed and connected to the adhesive performance. Surface energy is related to the work of adhesion and finally to the adhesion itself. Besides, this can be also used to estimate blend miscibility as reported by Siročić et al. [20].

Viscoelastic properties and surface properties are appropriate to characterize the effect of materials and technological parameters on the adhesive performance of polymer blends utilized as model HMPSAs comprising tackifiers of different chemical nature and concentrations. The employed tackifiers were rosin ester resin, hydrogenated and partially hydrogenated $\mathrm{C} 9$ hydrocarbon resins having a similar softening point $\left(100^{\circ} \mathrm{C}\right)$. These tackifiers were selected because of their different compatibility with the midblock and with the end-block of the SIS triblock copolymer. The hot melt pressure sensitive adhesives were melt-blended and melt-coated since these two methods are relevant and commonly used for preparing HMPSA.

\section{Experimental}

\subsection{Materials and processing}

Three different types of tackifiers (or tackifying resins) were employed. Hydrogenated C9 hydrocarbon resin (Arkon P-100) and partially hydrogenated C9 hydrocarbon resin (Arkon M-100) were provided by Arakawa Europe GmbH, Böhlen, Germany. Pentaerythritol rosin ester resin (Pensel GA 100) was provided by Arakawa Chemical Industries, Ltd, Osaka, Japan. Properties of resins employed in the present work are shown in Table 1.

Poly(styrene-block-isoprene-block-styrene) Kraton ${ }^{\mathrm{TM}}$ D1161PT (SIS) (Kraton Polymers LLC, Houston,

Table 1. Properties of resins employed in the polymer blends.

\begin{tabular}{|l|l|l|c|c|c|c|c|}
\hline Code & Trade name & $\begin{array}{c}\text { Classification acc. to } \\
\text { origin/ process }\end{array}$ & $\begin{array}{c}\mathbf{R} \& \mathbf{B} \text { soft. point } \\
{\left[{ }^{\circ} \mathbf{C}\right]}\end{array}$ & $\begin{array}{c}\text { Glass transition temperature } \\
{\left[{ }^{\circ} \mathbf{C}\right]}\end{array}$ & $\begin{array}{c}\boldsymbol{M}_{\mathbf{w}} \\
{\left[\mathbf{g} \cdot \mathbf{m o l}^{-1} \mathbf{l}\right.}\end{array}$ & $\begin{array}{c}\boldsymbol{M}_{\mathbf{n}} \\
{\left[\mathbf{g} \cdot \mathbf{m o l}^{-1}\right]}\end{array}$ & $\begin{array}{c}\boldsymbol{M}_{\mathbf{w}} / \boldsymbol{M}_{\mathbf{n}} \\
{[-]}\end{array}$ \\
\hline HC9 & Arkon P-100 & $\begin{array}{l}\text { Hydrogenated C9 hy- } \\
\text { drocarbon resin }\end{array}$ & 102 & 48 & 930 & 530 & 1.75 \\
\hline PHC9 & Arkon M-100 & $\begin{array}{l}\text { Partially hydrogenated } \\
\text { C9 hydrocarbon resin }\end{array}$ & 101 & 48 & 535 & 535 & 1.75 \\
\hline RE & Pensel GA 100 & $\begin{array}{l}\text { Pentaerythritol rosin } \\
\text { ester resin }\end{array}$ & 104 & 58 & 1130 & 700 & 1.61 \\
\hline
\end{tabular}

Table 2. Properties of copolymers used in the blends.

\begin{tabular}{|c|c|c|c|c|}
\hline Polymer & $\begin{array}{c}\boldsymbol{T}_{\mathrm{g}} \text { (elast. part) }^{\mathrm{a}} \\
{\left[{ }^{\circ} \mathbf{C}\right]}\end{array}$ & $\begin{array}{c}\boldsymbol{T}_{\mathrm{g}} \text { (glassy part) }^{\mathrm{a}} \\
{\left[{ }^{\circ} \mathbf{C}\right]}\end{array}$ & $\begin{array}{c}\text { Diblock [21] } \\
{[\mathbf{w t} \%]}\end{array}$ & $\begin{array}{c}\text { Styrene [21] } \\
{[\mathbf{w t} \%]}\end{array}$ \\
\hline SIS & -60 & +115 & 19 & 15 \\
\hline
\end{tabular}

${ }^{a}$ Glass transition temperature determined by means of mechanical spectrometer MCR 501 (Anton Paar GmbH, Graz, Austria) according to ISO 6721-7. 
USA) with $15 \mathrm{wt} \%$ styrene and $19 \mathrm{wt} \%$ Polystyreneblock-polyisoprene copolymer diblock was used [21, 22]. Properties of SIS are shown in Table 2.

Paraffinic oil (Shell Deutschland Oil GmbH, Hamburg, Germany) with a kinematic viscosity at $40^{\circ} \mathrm{C}$ of $108 \mathrm{~mm}^{2} / \mathrm{s}$ and a refractive index at $20^{\circ} \mathrm{C}$ of 1.478 (Shell Deutschland Oil GmbH, Hamburg, Germany) was used.

4,6-bis((octylthiomethyl)-o-cresol), Irganox 1520 produced by BASF (Ludwigshafen, Germany) was used as an antioxidant.

The samples used for the compatibility investigation were prepared in metal beakers containing a total of $100 \mathrm{~g}$ of materials. They were mixed using a stirrer at $50 \mathrm{rpm}$ RW $28 \mathrm{~W}$ (Janke \& Kunkel, VWR International $\mathrm{GmbH}$, Darmstadt, Germany) for $40 \mathrm{~min}$ at $170^{\circ} \mathrm{C}$. For compatibility study between styrenic block copolymer and resins, samples containing 20/30/50/70 parts by weight of SIS, 80/70/50/30 parts by weight of resin were prepared. In order to reduce thermal degradation, 1 part by weight of anti-oxidant was used. Resins used were hydrogenated $\mathrm{C} 9$ hydrocarbon resin, partially hydrogenated C9 hydrocarbon resin, and pentaerythritol rosin ester resin.

For compatibility study between polymers and oil, a blend comprising $80 \mathrm{wt} \%$ SIS and $19 \mathrm{wt} \%$ oil was prepared. Paraffinic oil was used. $1 \mathrm{wt} \%$ anti-oxidant was added.

The blends intended to be hot melt pressure sensitive adhesives models were blended using a laboratory kneader LUK 1.0 (Werner \& Pfleiderer, Stuttgart, Germany) with sigma blades. The set temperatures ranged from 180 to $190^{\circ} \mathrm{C}$, which corresponds to a final internal temperature of 149 and $155^{\circ} \mathrm{C}$, depending on the processed polymer at $55 \mathrm{rpm}$ (rotation per minute). The total mixing time was $80 \mathrm{~min}$ utes. The samples comprised SIS in three concentrations $(64 / 25 / 16 \mathrm{wt} \%)$, resins in three concentrations $(16 / 55 / 64 \mathrm{wt} \%), 19 \mathrm{wt} \%$ paraffinic oil and $1 \mathrm{wt} \%$ anti-oxidant. The resins used were hydrogenated $\mathrm{C} 9$ hydrocarbon resin, partially hydrogenated $\mathrm{C} 9$ hydrocarbon resin and pentaerythritol rosin ester resin. The tapes were prepared on a Nordson Meltex ${ }^{\circledR}$ Hot Melt Laboratory Coater CL 2018 S (Nordson Engineering $\mathrm{GmbH}$, Lüneburg, Germany) operating in the temperature range of 120 to $170^{\circ} \mathrm{C}$ and a coating speed of $3 \mathrm{~m} / \mathrm{min}$ using a gear pump operating at $18 \mathrm{rpm}$. A slot die was used to coat the molten blend on polyester film and further supported by a double-side siliconized paper. Films of $35 \pm 2 \mathrm{~g} / \mathrm{m}^{2}$ coating weight were produced.

\subsection{Materials characterization and instrumentation}

The dynamic mechanical analysis (DMA) measurements for the prepared blends were performed by a mechanical spectrometer Bohlin CVO HR120 (Malvern Instruments, Worcestershire, UK). The temperature range was -25 to $130^{\circ} \mathrm{C}$. The cooling run was performed and analyzed with a cooling rate of $2{ }^{\circ} \mathrm{C} / \mathrm{min}$ at oscillation mode at $1 \mathrm{~Hz}$ frequency using the plate-plate geometry of $20 \mathrm{~mm}$ diameter. For frequency sweep, the temperature was set to $25^{\circ} \mathrm{C}$ with a frequency range of 0.01 to $100 \mathrm{rad} / \mathrm{s}$ using plateplate geometry of $20 \mathrm{~mm}$ diameter.

The DMA tests for the neat SIS and its respective blend with paraffinic oil were performed according to ISO 6721-7 using a mechanical spectrometer MCR 501 (Anton Paar GmbH, Graz, Austria) in torsion mode at $1 \mathrm{~Hz}$. The heating run was performed and analyzed in the temperature range of -100 to $150^{\circ} \mathrm{C}$ and a heating rate of $2 \mathrm{~K} / \mathrm{min}$ at torsion mode at $1 \mathrm{~Hz}$ and $0.05 \%$ strain. The dimension of the samples was $30 \mathrm{~mm} \times 10 \mathrm{~mm} \times 2 \mathrm{~mm}$ made from pressed plates prepared at $160^{\circ} \mathrm{C}$.

The glass transition temperatures of the resins were determined by Differential scanning calorimetry (DSC), using a DSC 822 (Mettler Toledo Inc., Columbus, USA) at heating and cooling rates of $10 \mathrm{~K} / \mathrm{min}$ each. The first heating run was from -60 to $200^{\circ} \mathrm{C}$ and back to $-60^{\circ} \mathrm{C}$. It was held at $-60^{\circ} \mathrm{C}$ for $10 \mathrm{~min}$. The second heat run was from -60 to $300^{\circ} \mathrm{C}$, and the glass transition temperature was determined from the second run.

Fox equation (Equation (1)) is one of the empirical formulas proposed to calculate the glass transition temperature of a mixture [23]:

$$
\frac{1}{T_{\mathrm{g}}^{\mathrm{m}}}=\frac{X_{\mathrm{a}}}{T_{\mathrm{g}}^{\mathrm{a}}}+\frac{X_{\mathrm{b}}}{T_{\mathrm{g}}^{\mathrm{b}}}
$$

where $T_{\mathrm{g}}^{\mathrm{m}}$ is the glass transition temperature of the mixture containing component $a$ and $b ; T_{\mathrm{g}}^{\mathrm{a}}$ is the glass transition temperature of component $a$; $T_{\mathrm{g}}^{\mathrm{b}}$ is the glass transition temperature of component $\mathrm{b} ; X_{\mathrm{a}}$ and $X_{\mathrm{b}}$ are the weight fraction of components $a$ and $b$, respectively.

The Ring and ball softening point tests were carried out at the Petrotest RKA-2 (Petrotest Instruments 
GmbH \& Co. KG, Ostfildern, Germany) according to ASTM E-28.

Contact angle measurements were performed using a drop shape analyzer DSA 100 (Krüss, Hamburg, Germany) by the sessile drop method. A $20 \mu \mathrm{l}$ drop was deposited on the material surface, and three liquids were used for the measurements, namely water, diiodomethane and ethylene glycol. The surface energy and work of adhesion of the pure materials as well as of selected blends could be determined by applying the Owens, Wendt, Rabel and Kaelbe equation (OWRK).

Peel adhesion strength measurements at $180^{\circ}$ were performed according to PSTC-1 using the tensile strength tester UPM 1446 (Zwick GmbH, Ulm, Germany). Tapes of $220 \mathrm{~mm} \times 25 \mathrm{~mm}$ were prepared from the coated material and tested against two substrates, namely steel, and polyethylene. The peeling rate was $300 \mathrm{~mm} / \mathrm{min}$.

Shear adhesion (holding power) measurements were carried out on a Shear tester HT-8 (ChemInstruments, Fairfield, USA) according to PSTC-107. The samples were measured at 40 and $60^{\circ} \mathrm{C}$ with a $1 \mathrm{~kg}$ weight, and the falling time was recorded.

Loop Tack measurements were conducted according to DIN EN 1719 using the tensile strength tester UPM 1446 (Zwick GmbH, Ulm, Germany). Samples of $175 \mathrm{~mm} \times 25 \mathrm{~mm}$ were prepared and tested in a loop configuration. It was tested against steel with a peeling rate of $300 \mathrm{~mm} / \mathrm{min}$.

Gel permeation chromatography (SECcurity GPC system), (PSS GmbH, Mainz, Germany) was performed with a column combination of pre-column (PSS SDV $5 \mu \mathrm{m}$ ), column 1 (PSS SDV $5 \mu \mathrm{m}$, $1000 \mathrm{~A}$ ), column 2 (PSS SDV $5 \mu \mathrm{m}, 100000 \mathrm{~A}$ ) and column 3 (PSS SDV $5 \mu \mathrm{m}, 1000000 \mathrm{~A}$ ) and a SECurity differential refractometer detector. $20 \mathrm{mg}$ of each sample was dissolved in $5 \mathrm{ml}$ tetrahydrofuran (THF) for 24 hours. The calibration was carried out based on polystyrene standards.

\section{Results and discussion}

\subsection{Compatibility investigation}

Compatibility was studied by means of dynamic mechanical analysis. Polymer blends compatibility can be assessed by analyzing the glass transition temperature of the blends measured by this indirect method. A system presents a good degree of compatibility with the elastomeric part of the styrenic block copolymer if a pronounced shift of the maximum of the loss angle

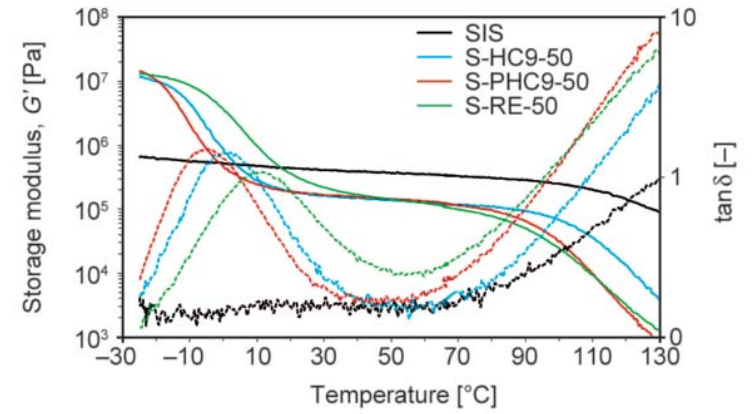

Figure 1. Storage modulus (full lines) and loss factor (dashed lines) for pure SIS and 50:50 blends comprising SIS and chosen tackifiers.

curve (glass transition temperature) of the elastomer to higher temperatures is achieved and if a decrease in the storage modulus value in the rubbery plateau region is observed $[3,17,18]$. The effect of the resins' chemical structure on glass transition temperature values for blends containing SIS is shown in Figure 1 and it can be observed that S-HC9-50, S-PHC9-50, and S-RE-50 show a relevant shift of the glass transition temperature to higher values in comparison to pure SIS for the elastomeric part of the block copolymer $\left(T_{\mathrm{g}}=-60^{\circ} \mathrm{C}\right.$, as described in Table 2).

The glass transition temperatures for neat resins (Table 1) were determined by DSC, whilst for the neat SIS (Table 2) as well as blends containing SIS and tackifiers, they were determined by identifying the temperature at maximum of loss modulus curves and compared to the calculated values predicted by Fox equation (Equation (1)) [23].

The comparison between the measured and accounted values of $T_{\mathrm{g}}$ has been also used as the criterion for the assessment of compatibility. The results are displayed in Figure 2.

According to this criterion, only the blend containing partially hydrogenated $\mathrm{C} 9$ hydrocarbon resin shows congruence with the calculated value, as shown in Figure 2a. However, substantial deviations were not observed for the other two blends. Figure $2 b$ shows a less satisfactory congruence between the calculated and measured values for the end-block region in the following order: hydrogenated C9 hydrocarbon resin, partially hydrogenated C9 hydrocarbon resin and rosin ester resin. Hence, rosin ester resin presents a relevant association with the elastomeric matrix and the dispersed glassy phase.

The effect of resins concentration on compatibility with SIS midblock is shown in Figure 3 as a result of mixtures containing SIS and hydrogenated C9 hydrocarbon resin. 

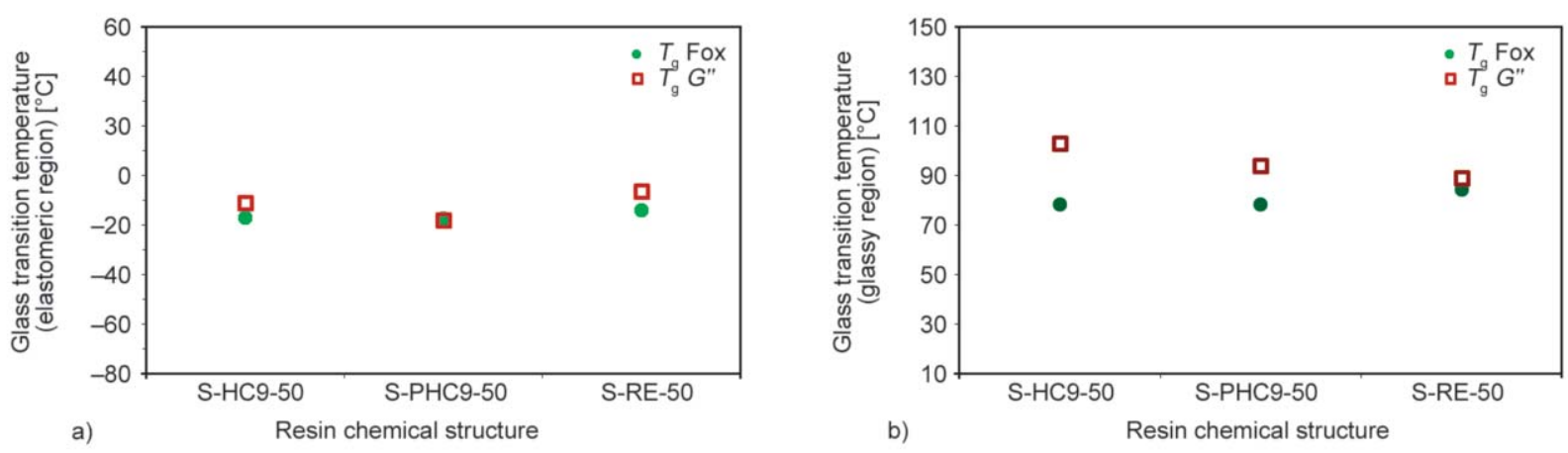

Figure 2. Glass transition temperature measured (temperature of maximum of $G^{\prime \prime}$ curve) and calculated by Fox equation for blends with resins and SIS 1:1 for the elastomeric region (a) and for the glassy region (b).

Systems containing SIS and resins presented a better correspondence with the predicted values in a concentration of around $50 \mathrm{wt} \%$ of the resin. As observed by Kamagata et al. [24] for systems containing pentaerythritol ester resin and natural rubber, a homogeneous phase in their system was observed up to $40 \mathrm{wt} \%$ resin. For higher resin concentration systems, they stated that a phase separation occurred [24]. An additional investigation considering the effect of oils on compatibility, which are used as plasticizers in HMPSAs blends, was conducted by means of dynamic mechanical analysis too. The viscoelastic properties are presented in Figure 4, showing data for neat SIS, a blend of $80 \mathrm{wt} \%$ SIS and $20 \mathrm{wt} \%$ paraffinic oil.

The general effect of a plasticizer is confirmed in the measurements. A decrease in glass transition temperature of the blend in comparison to the neat SIS was observed as well as a decrease in storage modulus. Plasticizers are known to dissolve in the polymer and to ease the polymer chains mobility [25].

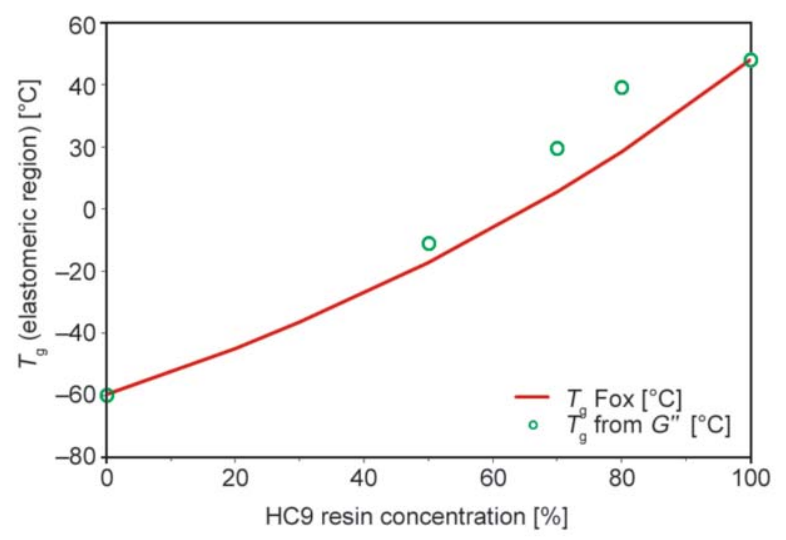

Figure 3. Glass transition temperature as function of .resin content for blends of SIS/hydrogenated C9 hydrocarbon resin for the elastomeric region; Open symbols are used for the experimental values from loss modulus values measured by DMA, red curves represent the calculated values by Fox equation.

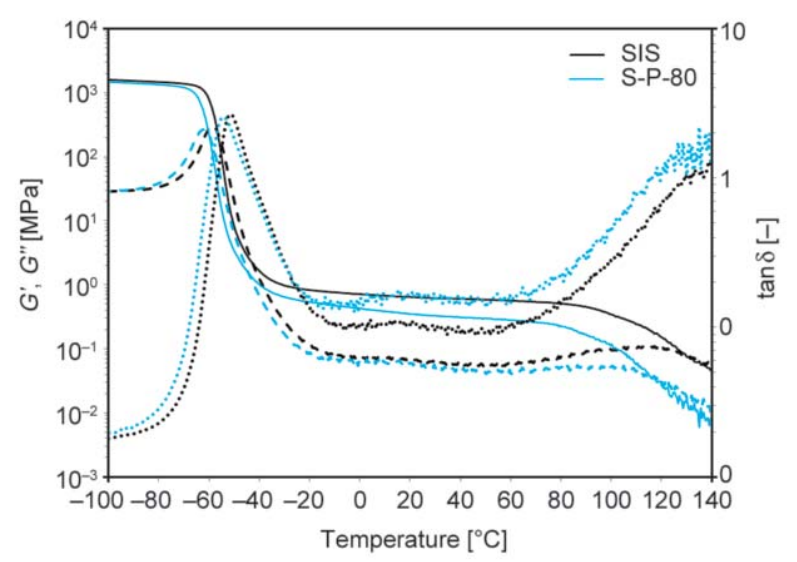

Figure 4. Storage modulus (full line), loss modulus (dashed lines) and loss factor (dotted lines) for neat SIS (grey lines) and blend of $80 \mathrm{wt} \%$ SIS $/ 20 \mathrm{wt} \%$ paraffinic oil (blue lines).

\subsection{Viscoelastic behavior of hot melt pressure sensitive adhesive blends}

Viscoelastic properties of polymer blends prepared as models of hot melt pressure sensitive adhesives were investigated regarding tackifier nature and concentration.

A good compatibility between the elastomeric part of the styrenic block copolymer and the tackifier is essential to bring pressure-sensitive characteristics to the adhesive. If good compatibility between the midblock of the styrenic block copolymer and the resin is present, a decrease in the storage modulus in the rubbery plateau region is to be expected as well as an increase in glass transition temperature of the elastomeric region.

Figure 5 displays storage modulus and loss factor curves (a) and loss modulus curves (b) for neat SIS as well as for HMPSAs models containing SIS, paraffinic oil and the resins examined.

It can be seen that for all the three blends, the storage modulus in the rubbery plateau region decreased in comparison to neat SIS and to a level lower than the 

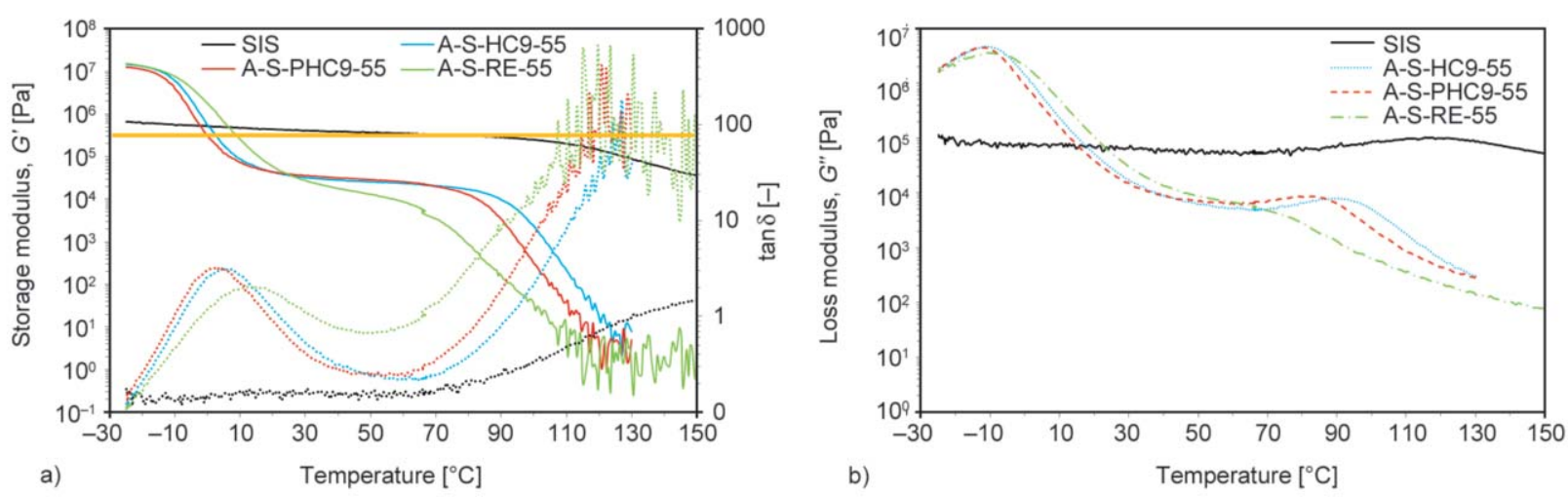

Figure 5. (a) Storage modulus curves (full lines) and loss factor curves (dotted lines) and (b) loss modulus curves for blends HMPSAs. Yellow line depicts storage modulus value according to Dahlquist criterion.

Dahlquist criterion value, which is highlighted by the yellow line. The yellow line is positioned in a level were $G^{\prime}$ corresponds to $3 \cdot 10^{5} \mathrm{~Pa}$, which is known as the Dahlquist criterion [26]. This is recognized to be a limiting modulus value for an adhesive to exhibit characteristics of a PSA at application temperature. Also, relevant shifts in glass transition temperature values are observed. As shown in Table 2, the glass transition temperature for the elastomeric part of the SIS triblock copolymer is $-60^{\circ} \mathrm{C}$. Based on it, a pressure-sensitive character for these blends is expected to be achieved.

It can be observed from loss modulus curves in Figure $5 \mathrm{~b}$ that a shift towards lower temperatures in the glass transition region of the styrenic domains occurs, and it follows the same trend as observed in the compatibility investigation of blends containing 1 SIS: 1 resin. The blend containing natural resin shows a higher decrease in glass transition temperature for the glassy region, followed by the partially hydrogenated $\mathrm{C} 9$ hydrocarbon resin and finally by the hydrogenated resin. This is an indication of the better association of the end-block and the pentaerythritol rosin ester resin in comparison to the other two resins.

Figure 6 shows the effect of tackifier concentration in blends containing hydrogenated C9 hydrocarbon resin in comparison to neat SIS. The measurements were conducted between -30 and $130^{\circ} \mathrm{C}$, thus the glass transition temperature for the elastomeric part of neat SIS cannot be identified in Figure 6, but it is displayed in Figure 4.

A decrease in storage modulus occurs in the rubbery plateau region. Properties were determined at $25^{\circ} \mathrm{C}$ and this behavior can be observed for all the blends presented in Figure 6. The values of storage moduli measured at $25^{\circ} \mathrm{C}$ for all blends are lower than the

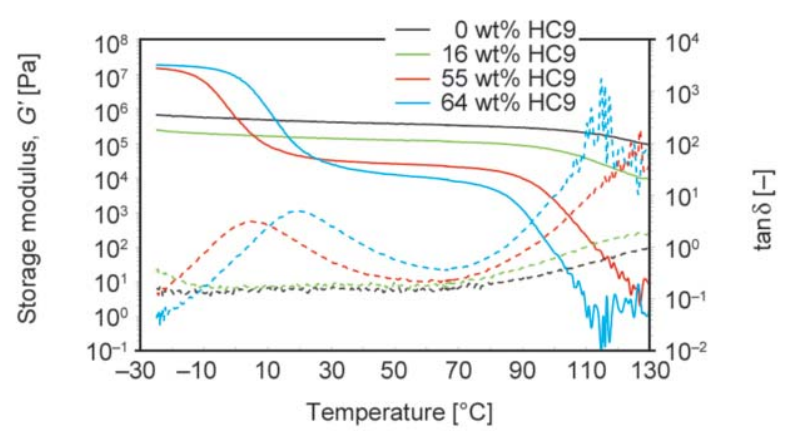

Figure 6. Storage modulus (full lines) and loss factor (dashed lines) curves for pure SIS (black curves), and $16 \mathrm{wt} \%$ resin (green curves), $55 \mathrm{wt} \%$ resin (red curves) and $64 \mathrm{wt} \%$ resin (blue curves) for HMPSAs blends comprising hydrogenated C9 hydrocarbon resin (A-S-HC9).

values of $G^{\prime}$ at $25^{\circ} \mathrm{C}$ of the pure SIS in the rubbery plateau region.

As the tackifier concentration in the blends increases, a decrease in storage modulus in the rubbery plateau occurs as well as an increase of the elastomeric glass transition temperature, as identified by the shift in the maximum of the loss factor curve.

\subsection{Surface properties of hot melt pressure sensitive adhesive blends}

The surface energies of the neat materials and the blends were determined by contact angle measurements as presented in Table 3 .

The results show that all blends possess surface energy lower than the surface energy of the stainless steel plate, which was used as a substrate for the peel tests. It is a condition generally to be fulfilled for good adhesion. It must be observed that the surface energy of the blends is much lower than the neat components' surface energy. The combination of these components leads to a system with lower free energy than the pure components and this is helpful for the 
Table 3. Surface energy for neat materials and HMPSAs blends comprising $55 \mathrm{wt} \%$ of tackifier.

\begin{tabular}{|l|c|c|c|}
\hline \multicolumn{1}{|c|}{ Sample } & $\begin{array}{c}\text { Surface } \\
\text { energy } \\
\text { (dispersive) } \\
{[\mathbf{m N} / \mathbf{m}]}\end{array}$ & $\begin{array}{c}\text { Surface } \\
\text { energy (polar) } \\
{[\mathbf{m N} / \mathbf{m}]}\end{array}$ & $\begin{array}{c}\text { Surface } \\
\text { energy total } \\
{[\mathbf{m N} / \mathbf{m}]}\end{array}$ \\
\hline Stainless steel & 37.94 & 7.10 & 45.03 \\
\hline SIS & 29.26 & 3.81 & 33.10 \\
\hline HC9 & 39.20 & 0.70 & 39.90 \\
\hline PHC9 & 39.60 & 1.50 & 41.10 \\
\hline RE & 41.30 & 1.40 & 42.70 \\
\hline A-S-HC9-55 & 20.07 & 0.01 & 20.08 \\
\hline A-S-PHC9-55 & 24.50 & 0.00 & 24.50 \\
\hline A-S-RE-55 & 27.80 & 0.20 & 28.00 \\
\hline
\end{tabular}

adhesion phenomenon. Thus, the thermodynamic adhesion mechanism may be one of the adhesion mechanisms occurring in such systems.

Siročić et al. [20] studied the miscibility for a blend composed of SAN and EPDM, using high impact polystyrene as a compatibilizer. In their study, they employed the surface energy value as an indicator for the blend miscibility trend and attempted to validate what they called 'minimum interfacial energy hypothesis'. The non-polar and acid-base interactions are the background for this hypothesis; when these interactions are at their highest level in a blend, the interfacial energy is at the lowest level. According to the authors, it can be interpreted that due to these interactions, the systems present lower surface energy values than pure materials. These results are consistent with the DMA curves, which showed that these systems show a satisfactory degree of compatibility. It is also observed that the measured polar components of the surface energy values are zero or close to zero, and these values are smaller than the pure materials polar components. According to Siročić et al. [20], this is an indication that the interactions between the phases present in the blends have a dispersive character.

\subsection{Tackiness}

In the work of Tse and coworkers [13, 27], a rheological model developed by them was employed to analyze the adhesive behavior of blends containing SIS and a C5 tackifying resin. In this model, the tack term for the PSA/stainless steel substrate interface is directly related to an intrinsic adhesion term, a bonding term, and a debonding term. These two last parameters are terms related to the viscoelastic properties of the bulk PSA. The bonding term depends

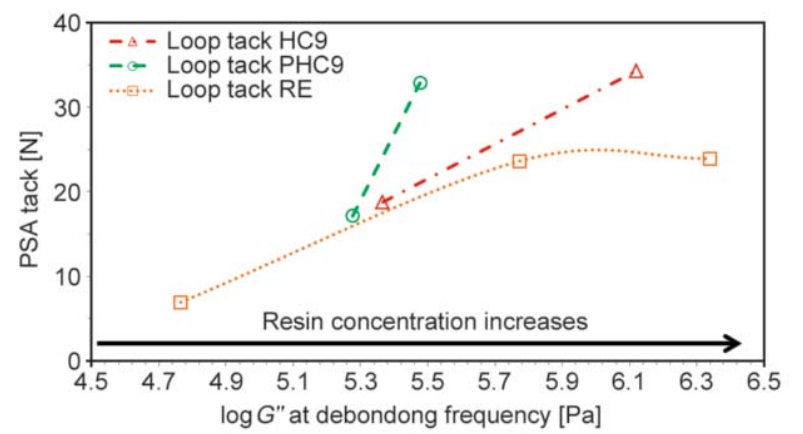

Figure 7. Loop tack correlation with logarithm loss modulus at debonding frequency of $100 \mathrm{rad} / \mathrm{s}$ at $25^{\circ} \mathrm{C}$.

on the plateau modulus of the adhesive as well as the contact time and pressure of the bond formation during the test. The debonding term is related to energy dissipation during the debonding process. They showed a satisfactory correlation for the debonding term with logarithm $G^{\prime \prime}$ at the debonding frequency and finally to the adhesive tack values.

Figure 7 shows such a correlation for the blends employed at different concentrations.

As stated by Chang [15], a frequency of $10^{2} \mathrm{~Hz}$ corresponds to the debonding frequency for a $50 \mu \mathrm{m}$ thick adhesive for a tack test conducted at $5 \mathrm{~mm} / \mathrm{s}$. In the present study, a $5 \mathrm{~mm} / \mathrm{s}$ loop tack test was conducted for samples with an average value of $50 \mu \mathrm{m}$ thickness. An adequate correlation was observed for all the samples indicating that a high dissipation is connected to the high tackiness of the adhesive. It can also be observed in Figure 7 that blends presenting higher log loss modulus at $100 \mathrm{rad} / \mathrm{s}$ comprising the same resin concentration on weight but of different chemical structure, also exhibit higher tackiness.

\subsection{Peel strength}

Intrinsic adhesion can be measured by means of contact angle as surface energy values and the order of magnitude of such contribution is of $10^{-1} \mathrm{~J} / \mathrm{m}^{2}$, while the terms related to the blend viscoelastic properties present values with an order of magnitude in the range of $10^{2}$ to $10^{4} \mathrm{~J} / \mathrm{m}^{2}[13,27]$.

As predicted by the viscoelastic properties measured by DMA, the polymer blends studied revealed a pressure-sensitive character with applicable peel strength values.

Figure 8 presents the adhesive performance results in relation to tackifier concentration in the blends. As tackifier concentration increases, peel strength increases. This is a general result mostly observed for PSAs. As the tackifier concentration increases and 


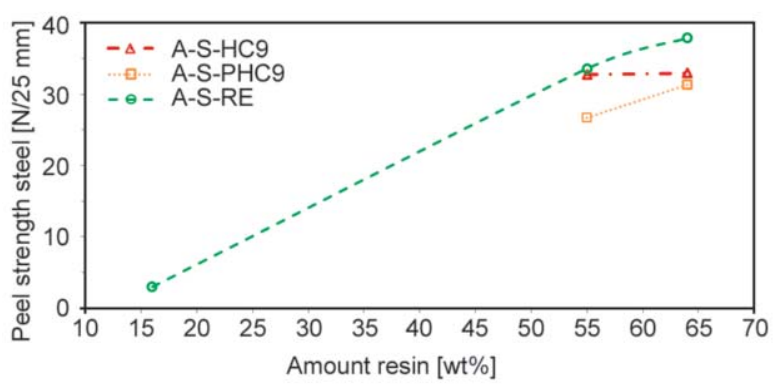

Figure 8. Peel strength in correlation to resin concentration.

the thermoplastic elastomer concentration decreases, the storage modulus in the plateau region decreases and this leads to lower peel strength. This result is in congruence with the viscoelastic properties measured by DMA.

\subsection{Shear adhesion (holding power)}

Figure 9 presents the shear adhesion performance results in relation to tackifier concentration in the blends measured by means of holding power. As the tackifier concentration increases, holding power decreases. This is a general result mostly observed for PSAs. Adhesion shear resistance (holding power) is an industrial method intended to measure HMPSA shear resistance. It can be performed at room temperature or elevated temperatures. At elevated temperatures, the failure mode (cohesion or adhesion) should be identified. However, it is not always easy to identify or to assure that only cohesion failure is happening and no adhesion (interfacial) failure is occurring. In the current work, mainly cohesion failure was observed.

Sosson et al. [28] studied the shear failure mechanism in chemically crosslinked PSAs by an own developed device in an attempt to determine in situ the PSAs failure micromechanisms. Considering

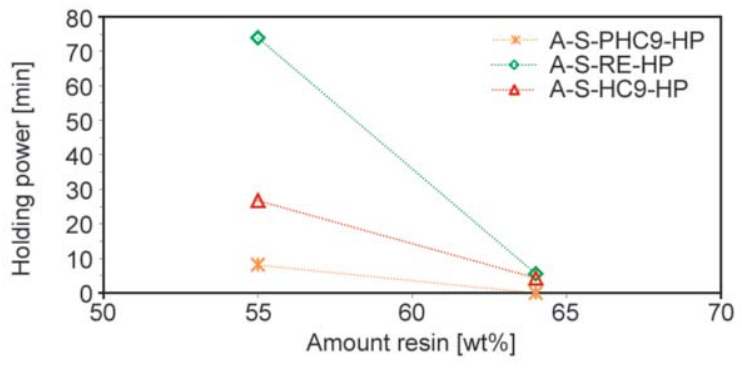

Figure 9. Shear adhesion holding power in correlation to resin concentration. For hydrogenated and partially hydrogenated C9 hydrocarbon resins, the holding power measurements were conducted at $60^{\circ} \mathrm{C}$, while for the rosin ester resin blend, the tests were conducted at $40^{\circ} \mathrm{C}$. the parameters analyzed, they could conclude that the crosslinking density plays an important role in the failure mechanism. For weakly crosslinked adhesive, a fluid-like behavior was observed, and failure occurred due to creep. For strongly crosslinked adhesive, the results suggest a fracture failure instead of creep failure. In the present study, holding power was determined at elevated temperatures to accelerate the testing procedures. These temperatures are above the glass transition of the elastomeric part of SIS and below the glass transition temperature of the dispersed polystyrene domains. Thus, polystyrene domains act like physical crosslinks in the blends.

From the holding power results obtained, it can be understood that less polystyrene is present in the formulation which means fewer physical crosslinks and due to the interaction of polystyrene and tackifier, as the tackifier amount increases, the glass transition temperature in the glassy part shifts to lower temperatures.

\section{Conclusions}

From the compatibility analysis conducted by the DMA method, it was observed that a good degree of association between SIS and the selected tackifiers exists regarding the elastomeric region, i.e. polyisoprene phase. For the glassy region, a higher degree of association was identified for rosin ester and the styrenic domains, followed by the partially hydrogenated C9 hydrocarbon resin and finally the hydrogenated C9 hydrocarbon resin.

A decrease in storage modulus in the rubbery plateau region was observed as well as an increase in glass transition temperature. These effects are attributed to an adequate association degree between the midblock of the SIS and the tackifiers employed. By increasing the resin concentration, the storage modulus in the rubbery plateau region decreases and the maximum loss factor curves shift to higher temperatures.

Surface energy was measured by means of contact angle method. It could be shown that all the blends presented lower surface energy values than the substrate. Thus, proper contact could be established between the adhesive and the adherent. Further on, surface energy was used to evaluate the compatibility's grade of the blends. The blends presented lower surface energy than the pure materials, due to non-polar and acid-base interactions. This is a characteristic of compatible blends. These results are in congruence 
with the DMA results, which showed that these systems exhibit a good degree of compatibility.

The adhesive performance was evaluated by measuring tackiness, peel and shear adhesion of the HMPSAs. PSA character was observed based on the obtained results of tack and peel for the blends. This effect was caused due to a good degree of compatibility with the tackifiers and the midblock. Those samples presenting higher dissipation at debonding frequency also presented higher tackiness results. The compatibility of the tackifiers and the end-block influenced shear adhesion. Holding power is related not only to the viscoelastic properties of the blends but also to the physical crosslinks present in the blends. The lowest holding power values were measured for the blends containing rosin ester resin and it is assumed that it occurs due to better association degree between the rosin ester resin and the styrenic domains. The styrene domains are pronouncedly disturbed by the rosin ester resin.

\section{References}

[1] Diethert A., Körstgens V., Magerl D., Ecker K., Perlich J., Roth S. V., Müller-Buschbaum P.: Structure and macroscopic tackiness of ultrathin pressure sensitive adhesive films. Applied Materials and Interfaces, 4, 39513958 (2012). https://doi.org/10.1021/am300774b

[2] Peykova Y., Lebedeva O. V., Diethert A., MüllerBuschbaum P., Willenbacher N.: Adhesive properties of acrylate copolymers: Effect of the nature of the substrate and copolymer functionality. International Journal of Adhesion and Adhesives, 34, 107-116 (2012). https://doi.org/10.1016/j.ijadhadh.2011.12.001

[3] Class J. B., Chu S. G.: The viscoelastic properties of rubber-resin blends. I. The effect of resin structure. Journal of Applied Polymer Science, 30, 805-814 (1985). https://doi.org/10.1002/app.1985.070300229

[4] O’Connor A. E., Macosko C. W.: Melt versus solvent coating: Structure and properties of block-copolymerbased pressure-sensitive adhesives. Journal of Applied Polymer Science, 86, 3355-3367 (2002).

https://doi.org/10.1002/app.11300

[5] Daoulas K. C., Theodorou D. N., Roos A., Creton C.: Experimental and self-consistent-field theoretical study of styrene block copolymer self-adhesive materials. Macromolecules, 37, 5093-5109 (2004).

https://doi.org/10.1021/ma035383a

[6] Utracki L. A., Shi Z. H.: Development of polymer blend morphology during compounding in a twin-screw extruder. Part I: Droplet dispersion and coalescence - A review. Polymer Engineering and Science, 32, 1824 1833 (1992).

https://doi.org/10.1002/pen.760322405
[7] McNaught A. D., Wilkinson A.: IUPAC compendium of chemical terminology. Blackwell Scientific Publications, Oxford (1997).

[8] Robeson L. M.: Polymer blends: A comprehensive review. Hanser, Munich (2007).

[9] Hayashi S., Kim H-J., Kajiyama M., Ono H., Mizumachi H., Zufu Z.: Miscibility and pressure-sensitive adhesive performances of acrylic copolymer and hydrogenated rosin systems. Journal of Applied Polymer Science, 71, 651-663 (1999).

https://doi.org/10.1002/(SICI)10974628(19990124)71:4<651::AID-APP17>3.0.CO;2-4

[10] Tobing S. D., Klein A.: Mechanistic studies in tackified acrylic emulsion pressure sensitive adhesives. Journal of Applied Polymer Science, 76, 1965-1976 (2000). https://doi.org/10.1002/(SICI)10974628(20000624)76:13<1965::AID-APP14>3.0.CO;2-Y

[11] Shih H-H., Hamed G. R.: Peel adhesion and viscoelasticity of poly(ethylene-co-vinyl acetate)-based hot melt adhesives. I. The effect of tackifier compatibility. Journal of Applied Polymer Science, 63, 323-331 (1997). https://doi.org/10.1002/(SICI)10974628(19970118)63:3<323::AID-APP7>3.0.CO;2-P

[12] Lim D-H., Do H-S., Kim H-J.: PSA performances and viscoelastic properties of SIS-based PSA blends with H-DCPD tackifiers. Journal of Applied Polymer Science, 102, 2839-2846 (2006).

https://doi.org/10.1002/app.24571

[13] Tse M. F.: Studies of triblock copolymer-tackifying resin interactions by viscoelasticity and adhesive performance. Journal of Adhesion Science and Technology, 3, 551-570 (1989). https://doi.org/10.1163/156856189X00407

[14] Chang E. P.: Viscoelastic properties of pressure-sensitive adhesives. The Journal of Adhesion, 60, 233-248 (1997). https://doi.org/10.1080/00218469708014421

[15] Chang E. P.: Viscoelastic windows of pressure-sensitive adhesives. The Journal of Adhesion, 34, 189-200 (1991). https://doi.org/10.1080/00218469108026513

[16] Aubrey D. W., Sherriff M.: Viscoelasticity of rubberresin mixtures. Journal of Applied Polymer Science : Polymer Chemistry Edition, 16, 2631-2643 (1978). https://doi.org/10.1002/pol.1978.170161017

[17] Class J. B., Chu S. G.: The viscoelastic properties of rubber-resin blends. II. The effect of resin molecular weight. Journal of Applied Polymer Science, 30, 815824 (1985). https://doi.org/10.1002/app.1985.070300230

[18] Class J. B., Chu S. G.: The viscoelastic properties of rubber-resin blends. III. The effect of resin concentration. Journal of Applied Polymer Science, 30, 825-842 (1985). https://doi.org/10.1002/app.1985.070300231 
[19] Gibert F. X., Marin G., Derail C., Allal A., Lechat J.: Rheological properties of hot melt pressure-sensitive adhesives based on styrene-isoprene copolymers. Part 1: A rheological model for [SIS-SI] formulations. The Journal of Adhesion, 79, 825-852 (2003). https://doi.org/10.1080/00218460309552

[20] Ptiček Siročić A., Hrnjak-Murgić Z., Jelenčić J.: The surface energy as an indicator of miscibility of SAN/ EDPM polymer blends. Journal of Adhesion Science and Technology, 27, 2615-2628 (2013).

https://doi.org/10.1080/01694243.2013.796279

[21] O’Brien E. P., Germinario L. T., Robe G. R., Williams T., Atkins D. G., Moroney D. A., Peters M. A.: Fundamentals of hot-melt pressure-sensitive adhesive tapes: The effect of tackifier aromaticity. Journal of Adhesion Science and Technology, 21, 637-661 (2007). https://doi.org/10.1163/156856107781192328

[22] Wu P., Qi S., Liu N., Deng K., Nie H.: Investigation of thermodynamic properties of SIS, SEBS and naphthenic oil by inverse gas chromatography. Journal of Elastomers and Plastics, 43, 369-386 (2011). https://doi.org/10.1177/0095244311405000
[23] Cantor A. S.: Glass transition temperatures of hydrocarbon blends: Adhesives measured by differential scanning calorimetry and dynamic mechanical analysis. Journal of Applied Polymer Science, 77, 826-832 (2000).

https://doi.org/10.1002/(SICI)10974628(20000725)77:4<826::AID-APP16>3.0.CO;2-7

[24] Kamagata K., Kosaka H., Hino K., Toyama M.: On the internal structure of pressure-sensitive adhesives. Journal of Applied Polymer Science, 15, 483-500 (1971). https://doi.org/10.1002/app.1971.070150222

[25] Sperling L. H.: Introduction to physical polymer science. Wiley, Hoboken (2006).

[26] Dahlquist C. A., Patrick R. L.: Treatise on adhesion and adhesives. Marcel Dekker, New York (1969).

[27] Tse M. F., Jacob L.: Pressure sensitive adhesives based on Vector ${ }^{\circledR}$ SIS polymers I. Rheological model and adhesive design pathways. The Journal of Adhesion, 56, 79-95 (1996).

https://doi.org/10.1080/00218469608010500

[28] Sosson F., Chateauminois A., Creton C.: Investigation of shear failure mechanisms of pressure-sensitive adhesives. Journal of Polymer Science Part B: Polymer Physics, 43, 3316-3330 (2005).

https://doi.org/10.1002/polb.20619 